\title{
Coconut Dust Gypsums Board Building Material for Shielding Radiation and Buildup Factors
}

\author{
Kittisak SRIWONGSA ${ }^{1,2, *}$, Sunantasak RAVANGVONG ${ }^{3}$, \\ Kanokwan SANGTHON ${ }^{4}$, Boonyanuch KORNPONGGUN ${ }^{4}$ \\ and Punsak GLUMGLOMCHIT ${ }^{4}$
}

\author{
${ }^{I}$ Faculty of Education, Silpakorn University, Nakhon Pathom 73000, Thailand \\ ${ }^{2}$ The Demonstration School of Silpakorn University, Nakhon Pathom 73000, Thailand \\ ${ }^{3}$ Division of Science and Technology, Faculty of Science and Technology, \\ Phetchaburi Rajabhat University, Phetchaburi 76000, Thailand \\ ${ }^{4}$ Huahin Vitthayalai School, Hua-Hin, Prachuapkhirikhan 77110, Thailand
}

('Corresponding author's e-mail: sriwongsa_k@silpakorn.edu)

Received: 8 January 2020, Revised: 19 June 2020, Accepted: 29 July 2020

\begin{abstract}
The coconut dust gypsums were fabricated and investigated through shielding radiation properties, energy absorption buildup factor (EABF), and exposure buildup factor (EBF). The mass attenuation coefficient $\left(\mu_{\mathrm{m}}\right)$ was investigated by using the Compton scattering technique at energy $662 \mathrm{keV}$ and theoretical values of the mass attenuation coefficients were computed by using the WinXCom software program at different photon energies from $1 \mathrm{keV}-100 \mathrm{GeV}$. EABF and EBF values were computed by the Geometric Progression (G-P) fitting method at photon energies ranging between 0.015 and $15 \mathrm{MeV}$ up to deep penetration of 40 mean free path $(\mathrm{mfp})$. After the addition of coconut dust volume into gypsum board, it was found that $\mu_{\mathrm{m}}$ values of the experiment and theory were generally in a good agreement. The results also indicated that the $\mu_{\mathrm{m}}$ increased while the EABF and EBF decreased along with the increase in the coconut dust volume. The EABF and EBF values with photon energy and deep penetration for coconut dust gypsums were found at a minimum value, i.e., at low and high energy range whereas, at the intermediate energy range, it could become high. These results suggest that coconut dust gypsums can be used as shielding radiation building material.
\end{abstract}

Keywords: Buildup factors, Coconut dust, Gypsum, Shielding radiation, Exposure buildup factor, Geometric progression

\section{Introduction}

Recently, the use of radiations and radioisotopes has been increasing day-by-day in many fields, such as medicine, reactors, agriculture, food industry, space, and nuclear. The acknowledgement of the radiation dosimetry has become the favorite topic in physics radiation due to the danger of the radiation for human health, cell, and environment, causing refusals against ionizing radiation. This problem can be solved by 3 major methods namely distance, shielding, and time [1-4].

Gypsum is a basic and very useful material for shielding applications. The earliest known for centuries and used as a building material was in Anatolia around 6000 B.C. This material is being used for the objective of structuring of a building of nuclear facility construction, agriculture, industry, and direct shielding applications $[5,6]$.

In 2001, Gerward developed the WinXCom program and widely used for estimated attenuation coefficient radiation of many materials such as glasses, concrete, rock, cement, and gypsum $[1,5,14]$. In 
http://wjst.wu.ac.th

this context, the mass attenuation coefficient $\left(\mu_{\mathrm{m}}\right)$ of coconut dust gypsums has been investigated in the energy $662 \mathrm{keV}$ by the Compton scattering technique and computed using the WinXCom computer program. This work also includes a comparison of mass attenuation coefficients of coconut dust gypsums with ordinary concrete. The computation EABF and EBF values were using the G-P fitting method at energies range from $0.015-15 \mathrm{MeV}$ up to deep penetration $40 \mathrm{mfp}$.

\section{Materials and methods}

\section{Shielding radiation}

Three different types of coconut dust gypsums were started by mixing gypsum, coconut dust, starch, and water, after mixing poured samples into mold, the composition of coconut dust gypsum samples as shown in Table 1.

Table 1 The compositions of coconut dust gypsums (grams).

\begin{tabular}{ccccc}
\hline Code & Gypsum (g) & Coconut dust (g) & Starch $(\mathbf{g})$ & Water $(\mathbf{g})$ \\
\hline f1 & 69 & 1 & 10 & 20 \\
f2 & 69 & 2 & 10 & 20 \\
f3 & 69 & 3 & 10 & 20 \\
\hline
\end{tabular}

The mass attenuation coefficient $\left(\mu_{\mathrm{m}}\right)$ of coconut dust gypsums were investigated at the energy of $\gamma$ ray $662 \mathrm{keV}$. The energy of $\gamma$-ray has been obtained from ${ }^{137} \mathrm{Cs}$ radioactive sources. The investigation was acted using a well-calibrated $\gamma$-ray spectrometer that includes of $2^{\prime \prime} \times 2^{\prime \prime} \mathrm{NaI}(\mathrm{Tl})$ scintillation detector which has $8 \%$ energy solution at $662 \mathrm{keV}$ (BICRON model 2M2/2), with CANBERRA photomultiplier tube base model 802-5. A schematic diagram of the experimental setup was shown in Figure 1. The theoretical determination for mass attenuation coefficient values of the samples was calculated by the WinXCom program at energy $1 \mathrm{keV}$ to $100 \mathrm{GeV}$.

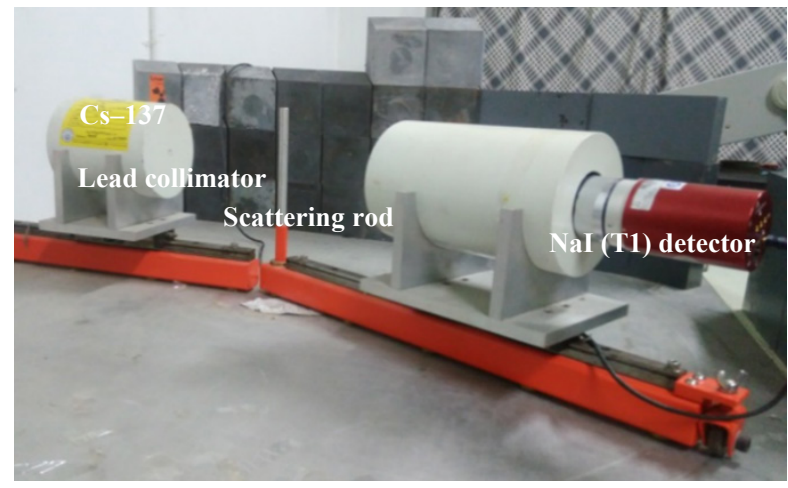

Figure 1 Experimental setup for transmission energy of $1 \mathrm{keV}-100 \mathrm{GeV}$.

The determination of attenuation coefficient for $\gamma$-ray was made by investigating the transmitted radiation intensity pass through-thickness $\mathrm{x}$ as compared to incident radiation intensity $I_{0}$. The linear attenuation coefficient $(\mu)$ was explained from exponential Beer-Lambert's law [7-9]: 
http://wjst.wu.ac.th

$\mathrm{I}=\mathrm{I}_{0} \cdot \mathrm{e}^{-\mu \mathrm{x}}$ $[10,11]$ :

The mass attenuation coefficients $\left(\mu_{\mathrm{m}}\right)$ of mediums were computed using the similar formula

$\mu_{\mathrm{m}}=\sum_{\mathrm{i}} \mathrm{w}_{\mathrm{i}}\left(\mu_{\mathrm{m}}\right)_{\mathrm{i}}$

here, $\mathrm{w}_{\mathrm{i}}$ is the weight fraction, $\mu_{\mathrm{m}}$ is the mass attenuation coefficient of the $\mathrm{i}^{\text {th }}$ element.

\section{Buildup factor}

The buildup factors and G-P fitting parameters for coconut dust gypsums were computed from the equivalent atomic number $\left(Z_{\mathrm{eq}}\right)$ by logarithmic interpolation method. The calculation was operated by three steps:

1. Computation of equivalent atomic number $\left(\mathrm{Z}_{\mathrm{eq}}\right)$;

2. Computation of G-P fitting parameter using interpolation method;

3. Computation of buildup factors $[12,15]$.

$\mathrm{Z}_{\mathrm{eq}}$ is a single parameter which explains properties for coconut dust gypsums in terms of equivalent elements and were computed from the ratio of $\left(\mu_{\mathrm{m}}\right)_{\text {Compton }}$ with $\left(\mu_{\mathrm{m}}\right)_{\text {total }}$ at same photon energies, using the formula $[12,13]$ :

$Z_{\text {eq }}=\frac{Z_{1}\left(\log R_{2}-\log R\right)+Z_{2}\left(\log R-\log R_{1}\right)}{\log R_{2}-\log R_{1}}$

where $Z_{1}$ and $Z_{2}$ are values of atomic numbers of elements according to ratios $R_{1}$ and $R_{2}$, respectively. $R$ is ratio $\left(\mu_{\mathrm{m}}\right)_{\text {Compton }} /\left(\mu_{\mathrm{m}}\right)_{\text {Total }}$ for coconut dust gypsums at the same energy. The parameters of G-P fitting are computed by the logarithmic interpolation method for $Z_{\text {eq. }}$. The parameters of G-P fitting for elements were taken report by the standard reference database, the American Nuclear Society ANSI/ANS-6.4.3. For coconut dust gypsums were using the formula $[12,13]$ :

$\mathrm{P}=\frac{\mathrm{P}_{1}\left(\log \mathrm{Z}_{2}-\log \mathrm{Z}_{\mathrm{eq}}\right)+\mathrm{P}_{2}\left(\log \mathrm{Z}_{\mathrm{eq}}-\log \mathrm{Z}_{1}\right)}{\log \mathrm{Z}_{2}-\log \mathrm{Z}_{1}}$

where $P_{1}$ and $P_{2}$ are parameters value of G-P fitting like atomic numbers of $Z_{1}$ and $Z_{2}$, respectively, at same energies. The parameters of G-P fitting of coconut dust gypsums were used to compute buildup factor as determined by $[12,13]$ :

$$
\mathrm{B}(\mathrm{E}, \mathrm{X})=1+\frac{\mathrm{b}-1}{\mathrm{~K}-1}\left(\mathrm{~K}^{\mathrm{x}}-1\right), \mathrm{K} \neq 1
$$

$\mathrm{B}(\mathrm{K}, \mathrm{X})=1+(\mathrm{b}-1) \mathrm{x}, \mathrm{K}=1$

and

$$
\mathrm{K}(\mathrm{E}, \mathrm{x})=\mathrm{cx} \mathrm{c}^{\mathrm{a}}+\mathrm{d} \frac{\tanh \left(\frac{\mathrm{x}}{\mathrm{x}_{\mathrm{K}}}-2\right)-\tanh (-2)}{1-\tanh (-2)}, \mathrm{x} \leq 40 \mathrm{mfp}
$$

where $\mathrm{E}$ and $\mathrm{x}$ are incident photon energies and penetration depth in terms of mean free path (mfp), respectively., a, b, c, d, and $\mathrm{X}_{\mathrm{K}}$ are G-P fitting parameters. $\mathrm{K}$ parameter with deep penetration indicates photon dose multiplication and adjusts in the configuration of the spectrum. 
http://wjst.wu.ac.th

\section{Results and discussion}

\section{Shielding radiation}

The $\mu_{\mathrm{m}}$ values for coconut dust gypsums were compared with ordinary concrete from simulation by the WinXcom program as shown in Figure 2. It was found that the $\mu_{\mathrm{m}}$ value of $\mathrm{f} 3$ had the highest value and all samples had a higher value than ordinary concrete. These indicated that coconut dust gypsums had shielding radiation properties better than ordinary concrete and $\mathrm{f} 3$ had the best shielding radiation properties. From Figure 2, graphs are not continuous due to the absorption edge of Silicon $\left(\mathrm{K} 1.84 \times 10^{-3}\right.$ $\mathrm{MeV})$, Sulfur $\left(\mathrm{K} 2.47 \times 10^{-3} \mathrm{MeV}\right)$, Potassium $\left(\mathrm{K} 3.61 \times 10^{-3} \mathrm{MeV}\right)$, Calcium $\left(\mathrm{K} 4.04 \times 10^{-3} \mathrm{MeV}\right)$, Titanium $\left(\mathrm{K} 4.97 \times 10^{-3} \mathrm{MeV}\right)$, Manganese $\left(\mathrm{K} 6.54 \times 10^{-3} \mathrm{MeV}\right)$, and Iron $\left(\mathrm{K} 7.11 \times 10^{-3} \mathrm{MeV}\right)$.

Table 2 The $\mu_{\mathrm{m}}$ for experimental and theoretical of coconut dust gypsums $\left(\mathrm{cm}^{2} / \mathrm{g}\right)$.

\begin{tabular}{ccccccc}
\hline \multirow{2}{*}{ Energy (keV) } & \multicolumn{2}{c}{$\mathbf{f 1}$} & \multicolumn{2}{c}{$\mathbf{f 2}$} & \multicolumn{2}{c}{$\mathbf{f 3}$} \\
\cline { 2 - 7 } & $\boldsymbol{\mu}_{\mathrm{m}}(\mathbf{t h})$ & $\mu_{\mathrm{m}}(\mathbf{e x})$ & $\mu_{\mathrm{m}}(\mathbf{t h})$ & $\mu_{\mathrm{m}}(\mathbf{e x})$ & $\mu_{\mathrm{m}}(\mathbf{t h})$ & $\boldsymbol{\mu}_{\mathrm{m}}(\mathbf{e x})$ \\
\hline 662.00 & 0.07735 & 0.07729 & 0.07735 & 0.07751 & 0.07737 & 0.07780 \\
\hline
\end{tabular}

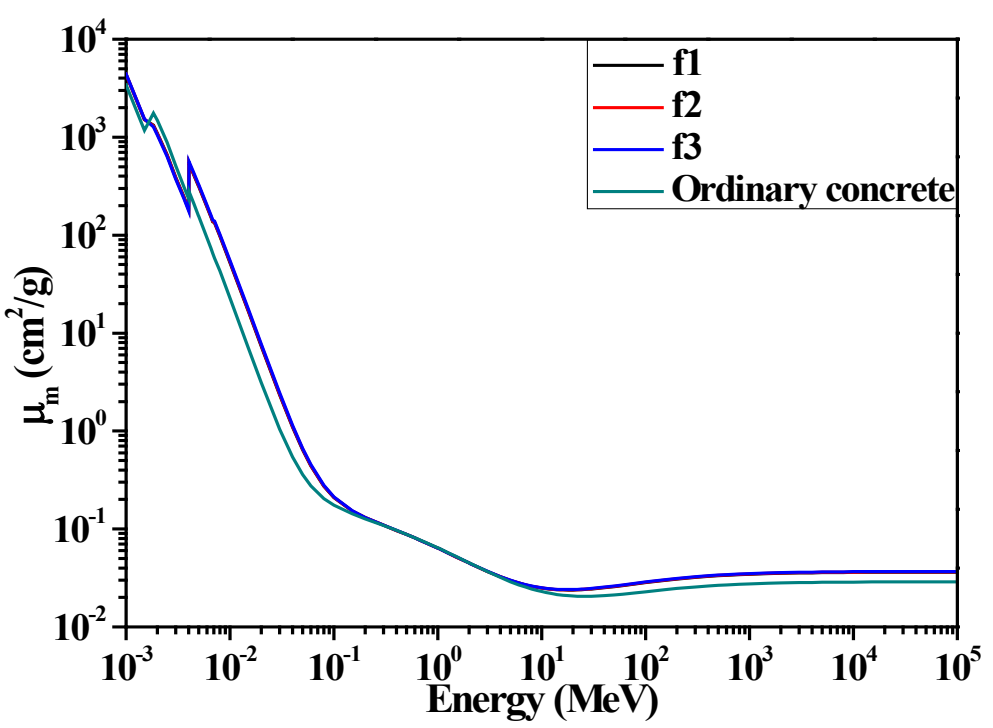

Figure $2 \mu_{\mathrm{m}}$ of coconut dust gypsums compared method using Compton scattering with ordinary concrete for photon technique. 

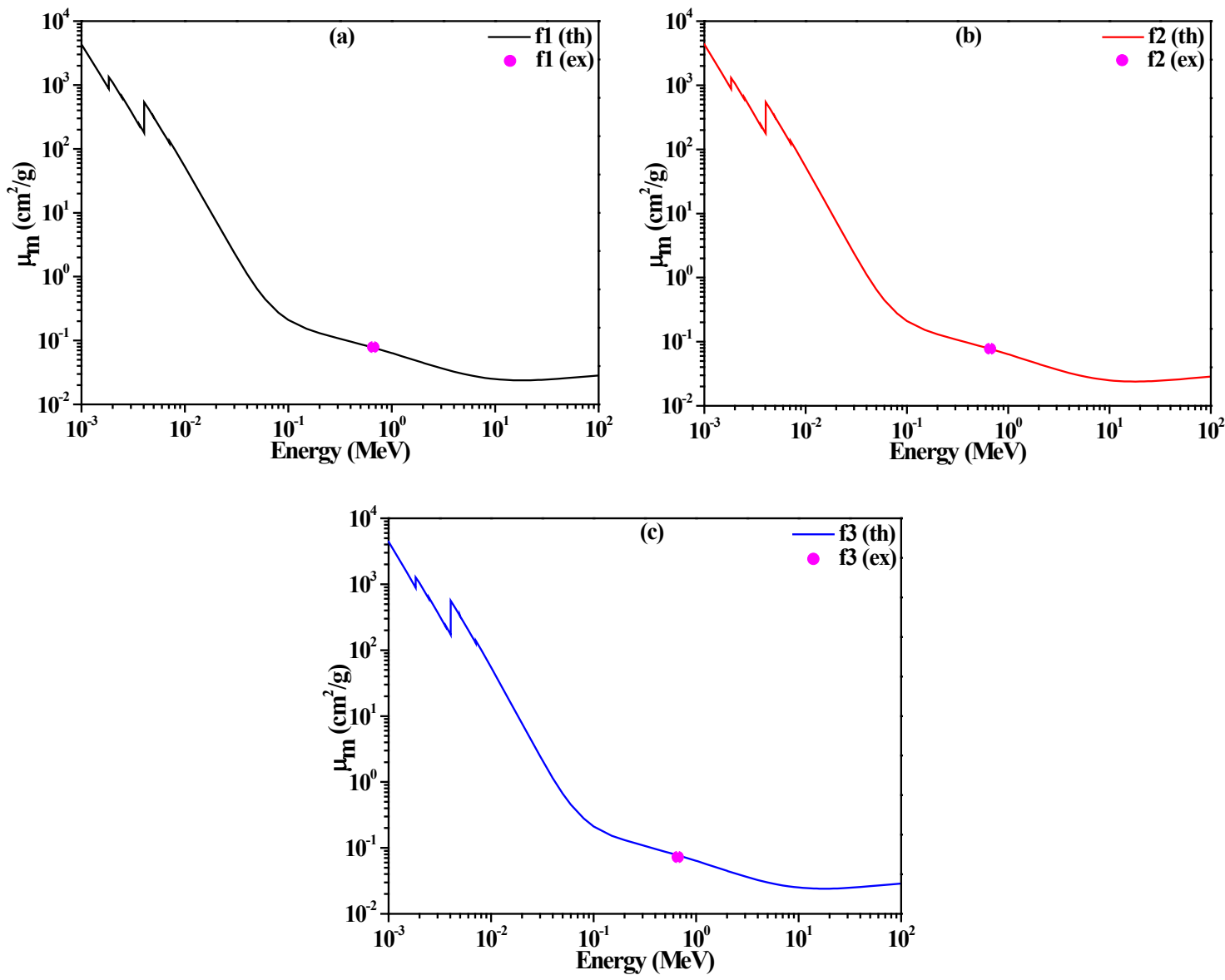

Figures 3 (a) - (c) The comparison $\mu_{m}$ of coconut dust gypsums between experimental and theoretical at a photon energy of $662 \mathrm{keV}$.

The $\mu_{\mathrm{m}}$ values from the experiment and theory were compared as seen in Figures 3(a) - 3(c). The experiment used the Compton scattering technique to determine $\mu_{\mathrm{m}}$ values at gamma ray energy $662 \mathrm{keV}$. The result indicated that $\mu_{\mathrm{m}}$ values increase along with the increasing coconut dust volume, implying the better shielding properties in this energy, and it was observed that the $\mu_{\mathrm{m}}$ values from experiment and theory were generally in a good agreement. As the interaction of the radiation with the medium depends on the material's volume, it is interesting to present $\mu_{\mathrm{m}}$ as a function of coconut dust's volume. This is illustrated in Figures 3(a) - 3(c) (at the photon energy of $662 \mathrm{keV}$ ) where it can be seen that $\mu_{\mathrm{m}}$ increases with an increase in coconut dust volume [8].

\section{Buildup factor}

Figure 4 gives equivalent atomic numbers $\left(Z_{\text {eq }}\right)$ of shielding radiation materials at an energy range from $0.015-15 \mathrm{MeV}$. This figure exhibits $Z_{\mathrm{eq}}$ dependence on coconut dust volume in which $Z_{\mathrm{eq}}$ increases with increasing coconut dust volume. 


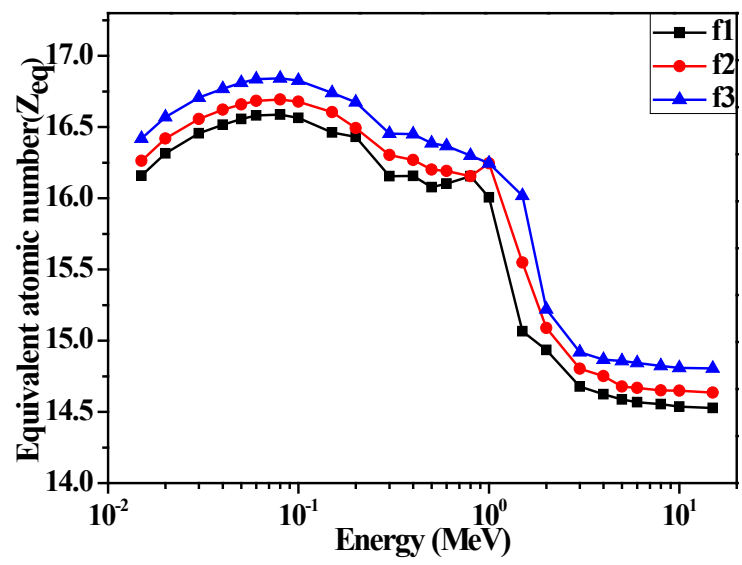

Figure $4 Z_{\text {eq }}$ of coconut dust gypsums.
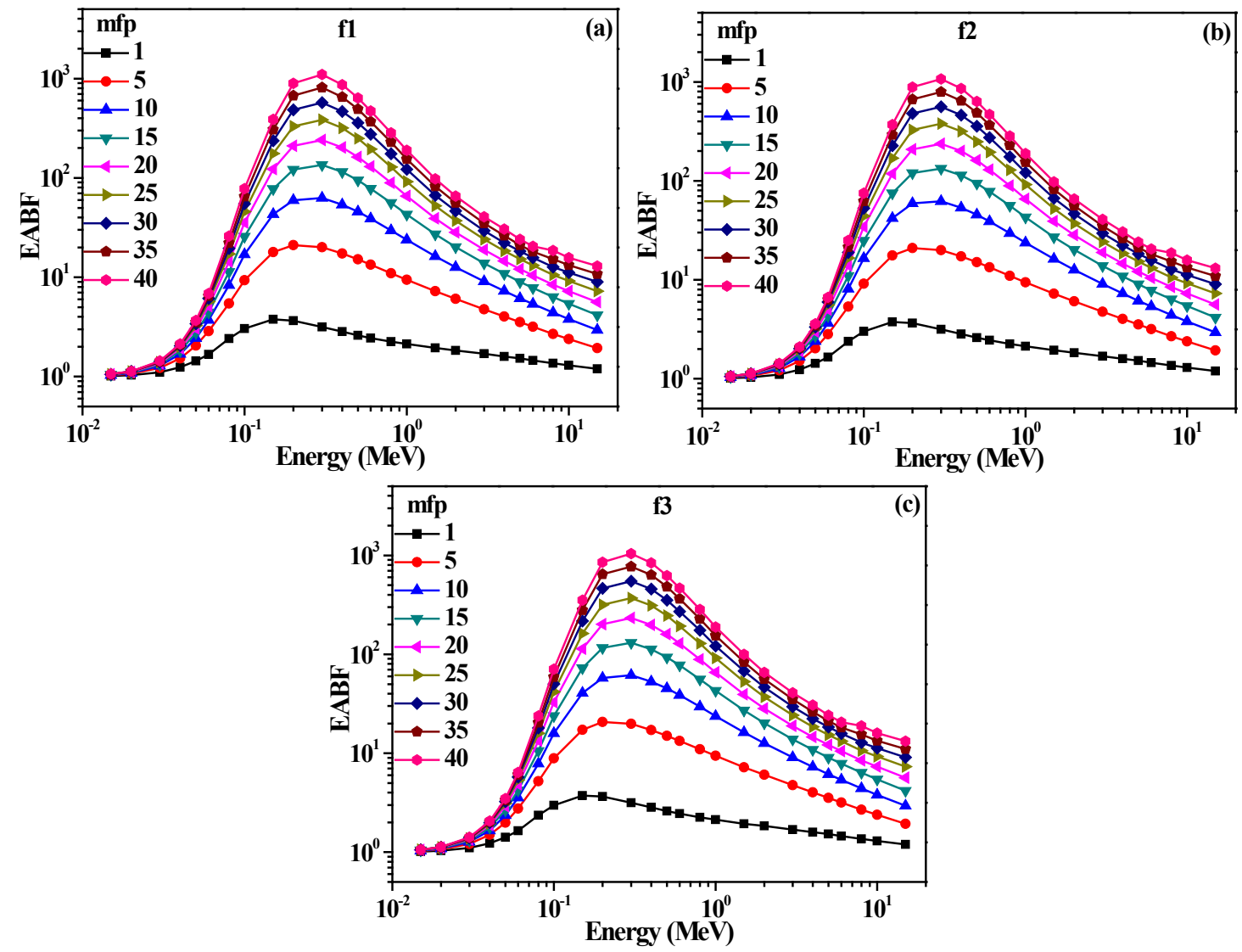

Figures 5 (a) - (c) EABF with energy for gypsums at 1, 5, 10, 15, 20, 25, 30, 35 and $40 \mathrm{mfp}$, respectively. 

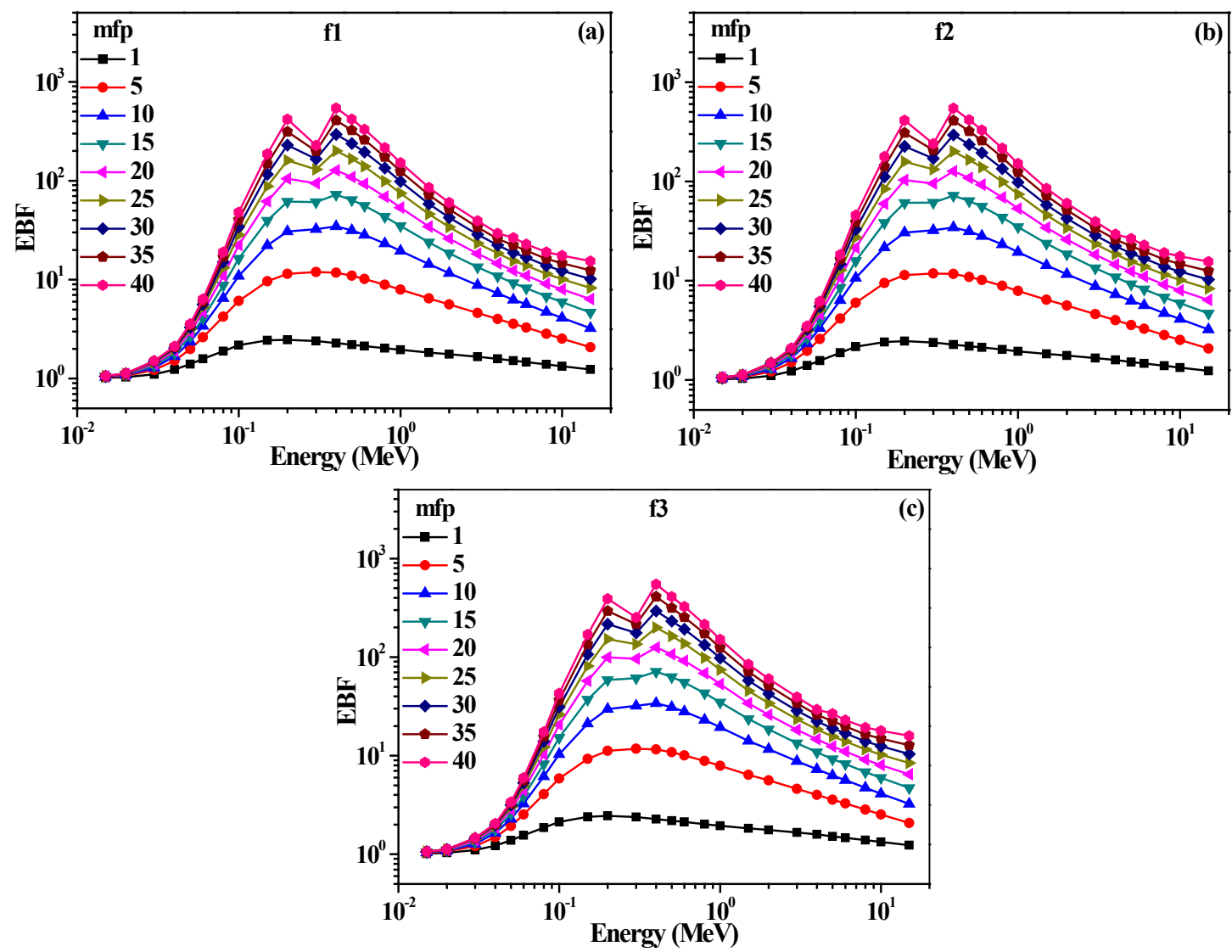

Figures 6 (a) - (c) EBF with energy for gypsums at 1, 5, 10, 15, 20, 25, 30, 35 and $40 \mathrm{mfp}$, respectively.

Figures 5(a) - 5(c) and Figures 6(a) - 6(c) exhibit the EABF and EBF with energies for coconut dust gypsums at $1,5,10,15,20,25,30,35$, and $40 \mathrm{mfp}$, respectively. The variation of the EABF and EBF with energies from 0.015 to $15.0 \mathrm{MeV}$, for coconut dust gypsums at the deep penetration of all mfp, are exhibited in the same trend of the EABF and EBF with energy. The variations of the EABF and EBF values of coconut dust gypsums with energy are shown in Figures 5(a) - 5(c) and Figures 6(a) - 6(c). It was found that the EABF and EBF values of coconut dust gypsums shielding radiation had a minimum value at the low and high energy range, while they had a higher value in the intermediate energy range. The buildup factors in low energies range were small because these energies were absorbed completely by the photoelectric absorption effect, or removed completely, gradually increasing with energy because of the multiple scatterings of a photon by the Compton scattering technique at the intermediate energy range and lastly, it decreased again at the high energy range because of the pair production. The maximum energy, $E_{\max }$, at which the EABF values were maximum for $\mathrm{fl}, \mathrm{f} 2$, and $\mathrm{f} 3$, was $0.3 \mathrm{MeV}$. The EBF of $\mathrm{f} 1, \mathrm{f} 2$, and $\mathrm{f} 3$ had two peaks at 0.2 and $0.4 \mathrm{MeV}$ because of the K-absorption edge of iron (Fe) composition elements in range and $\mathrm{E}_{\max }$ for the $\mathrm{EBF}$ values was $0.4 \mathrm{MeV}$. The analysis disclosed that $\mathrm{f3}$ was suitable for coconut dust gypsums shielding for photons as the low EABF and EBF values compared with other coconut dust gypsums for different energies were observed.

Figures 7(a) - 7(d) and Figures 8(a) - 8(d) displays the values of EABF and EBF with a deep penetration for coconut dust gypsums at $0.015,0.15,1.5$, and $15 \mathrm{MeV}$ energies, respectively. It was found that the EABF and EBF values of the coconut dust gypsums increased with the penetration depth initially. Both figures illustrate that at the low energy, the EABF and EBF are mfp loose. At the intermediate 
energy, EABF and EBF increase in value and at the high energy, EABF and EBF again decrease in value. These can be discussed on the basis of the partial photon interaction processes. At the low energy range, buildup factors had small values because the photoelectric effect was the main interaction affecting photons to move fast, not allowing them to accumulate in the medium. Therefore, both values indicated the dependence on chemicals compositions for gypsum at the lower energy range. At the intermediate energy, the EABF and EBF had large values because the Compton scattering technique was dominant affecting photons to bring multiple scatterings and accumulate in the medium. Therefore, both values show completeindependence on chemical compositions of gypsum at the intermediate energy range. At the high energy range, both values decreased because thepair production was dominant producing electron-positron pair $[15,16]$. Such process prevented photons from accumulating in the medium. From Figures 7 and $\mathbf{8}(\mathbf{b})$, it is evident that $\mathrm{f} 3$ had the greatest shielding effect.
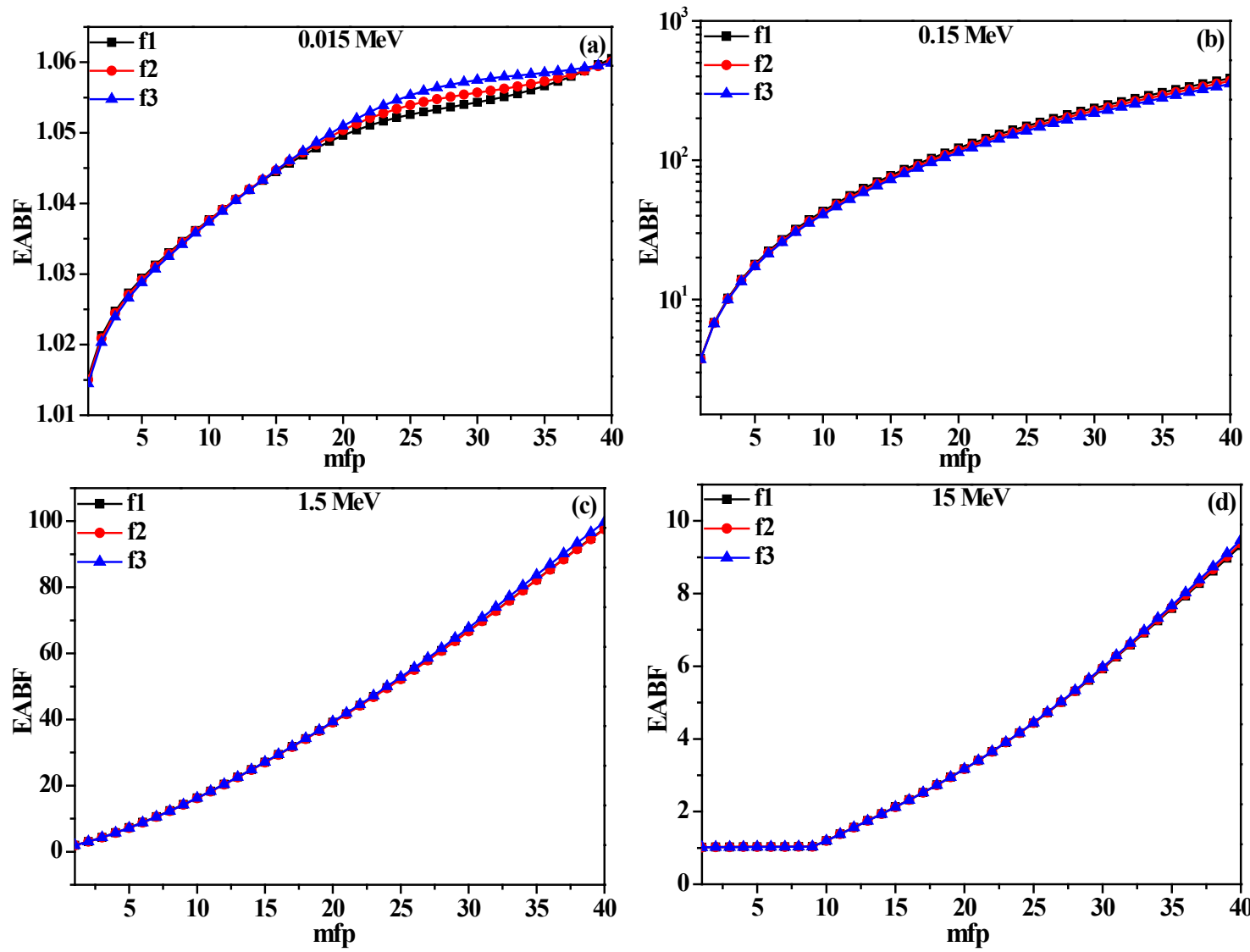

Figures 7 (a) - (d) EABF with deep penetration for coconut dust gypsums at $0.015,0.15,1.5$ and 15 $\mathrm{MeV}$, respectively. 

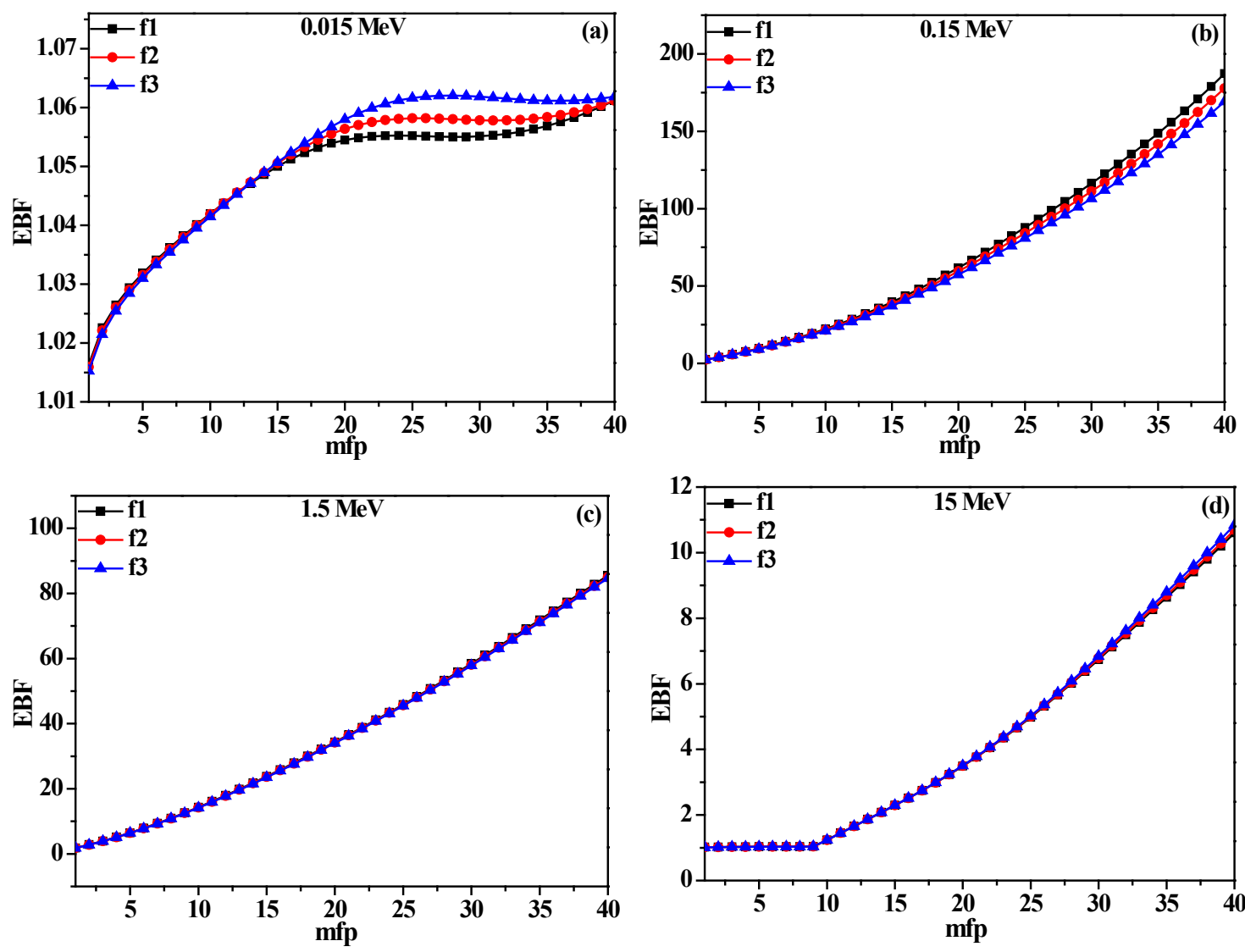

Figures 8 (a) - (d) EBF with penetration depth for coconut dust gypsums at 0.015, 0.15, 1.5 and $15 \mathrm{MeV}$, respectively.

\section{Conclusions}

$\gamma$-ray shielding properties of coconut dust gypsums were studied. Results of the mass attenuation coefficients increased along with an increase in the coconut dust gypsums volume and decreased along with an increase in the incident gamma ray energy and all samples had a higher value than ordinary concrete. These indicated that coconut dust gypsums had shielding radiation properties better than ordinary concrete. The sample materials were measured in terms of $\gamma$-ray, EABF, and EBF by the G-P fitting formula in energies region at $0.015-15 \mathrm{MeV}$ up to a penetration depth of $40 \mathrm{mfp}$. Significant increases in EABF and EBF were observed in the sample materials at the energy of $0.4 \mathrm{MeV}$, where the Compton scattering technique was predominated, in the same way as EABF and EBF with a penetration depth of coconut dust gypsums at $0.015,0.15,1.5$, and $15 \mathrm{MeV}$. The results suggested that the coconut dust gypsums that had more coconut dust was the greatest shielding $\gamma$-ray. These results encourage the use of coconut dust gypsums as shielding radiation building material.

\section{Acknowledgements}

The authors wish to thank the Nakhon Pathom Rajabhat University (NPRU) for supporting this research. 
http://wjst.wu.ac.th

\section{References}

[1] SS Obaid, DK Gaikwad and PP Pawar. Determination of gamma ray shielding parameters of rocks and concrete. Radiat. Phys. Chem. 2018; 144, 356-60.

[2] I Akkurt, H Akyildirim, B Mavi, S Kilincarslan and C Basyigit. Gamma-ray shielding properties of concrete including barite at different energies. Prog. Nucl. Energ. 2010; 52, 620-3.

[3] TAA Junior, MS. Nogueira, V Vivolo, MPA Potiens and LL Campos. Mass attenuation coefficients of X-rays in different barite concrete used in radiation protection as shielding against ionizing radiation. Radiat. Phys. Chem. 2017; 140, 349-54.

[4] HO Tekin, MI Sayyed and SAM Issa. Gamma radiation shielding properties of the hematiteserpentine concrete blended with WO3 and $\mathrm{Bi}_{2} \mathrm{O}_{3}$ micro and nano particles using MCNPX code. Radiat. Phys. Chem. 2018; 150, 95-100.

[5] HO Tekin, VP Singh, T Manici and EEA Guclu. Validation of MCNPX with experimental results of mass attenuation coefficients for cement, gypsum and mixture. J. Radiat. Protec. Res. 2017; 42, 154-7.

[6] AH Korna, S Fares, MA El-Rahman. Natural radioactivity levels and radiation hazards for gypsum materials used in Egypt. J. Environ. Sci. Technol. 2014; 7, 56-66.

[7] AS Ouda. Development of high-performance heavy density concrete using different aggregates for gamma-ray shielding. Prog. Nucl. Energ. 2015; 79, 48-55.

[8] I Akkurt, C Basyigit, S Kilincarslan, B Mavi and A Akkurt. Radiation shielding of concretes containing different aggregates. Cement Concrete Comp. 2006; 28, 153-7.

[9] I Akkurt and H Akylldırım. Radiation transmission of concrete including pumice for 662, 1173 and $1332 \mathrm{keV}$ gamma rays. Nucl. Eng. Des. 2012; 252, 163-6.

[10] ESA Waly and MA Bourham. Comparative study of different concrete composition as gamma-ray shielding materials. Ann. Nucl. Energy 2015; 85, 306-10.

[11] H O Tekin, TT Erguzel, MI Sayyed, VP Singh, T Manici, EE Altunsoy and O Agar. An investigation on shielding properties of different Granite samples using MCNPX code. Dig. J. Nanomater. Bios. 2018; 13, 381-9.

[12] VP Singh and NM Badiger. Comprehensive study on energy absorption buildup factors and exposure buildup factors for photon energy 0.015 to $15 \mathrm{MeV}$ up to $40 \mathrm{mfp}$ penetration depth for gel dosimeters. Radiat. Phys. Chem. 2014; 103, 234-42.

[13] VP Singh, NM Badiger and AM Ei-Khayatt. Study on $\gamma$-ray exposure buildup factors and fast neutron-shielding properties of some building materials. Radiat. Eff. Defects Solids 2014; 169, 54759 .

[14] MI Sayyed, SAM Issa, M Büyükyıldızc and M Dongd. Determination of nuclear radiation shielding properties of some tellurite glasses using MCNP5 code. Radiat. Phys. Chem. 2018; 150, 1-8.

[15] MI Sayyed and H Elhouichet. Variation of energy absorption and exposure buildup factors with incident photon energy and penetration depth for boro-tellurite $\left(\mathrm{B}_{2} \mathrm{O}_{3}-\mathrm{TeO}_{2}\right)$ glasses. Radiat. Phys. Chem. 2017; 130, 335-42.

[16] B Oto, N Yıldız, T Korkut and E Kavaz. Neutron shielding qualities and gamma ray buildup factors of concretes containing limonite ore. Nucl. Eng. Des. 2015; 293, 166-75. 